\title{
भारतीय - नदी सम्पदा
}

\section{- डॉ. रामपाल शुक्ल}

वैदिक तत्वों को स्फुटरूप से अवगत करने के लिए पुराणवांड्मय का आविर्भाव हुआ। महर्षि व्यास और उनके शिष्यों प्रशिष्यों ने वैदिक-वाणी को सामान्यजन तक संदेश देने के लिए पुराणों का प्रणयन कर संस्कृति और सभ्यता को प्रकाश में लाने का कार्य किया हैं। इनके अध्ययन से हम अपनी प्राचीन संस्कृति-सभ्यता और मूल्यों को समझ सकते हैं।

अतः इनके अध्ययन से सांस्कृतिक - भौगोलिक - सामाजिक और राजनीतिक रहस्यों को समझ सकते हैं। पुराणों में वर्णित भौगौलिक वर्णन में श्रीमद्भागवत का वर्णन अत्यंत सटीक एवं गहन है। इसके अध्ययन से ही हमें हमारी प्राकृतिक सम्पदा और नदियों का मूल रहस्य एवं तथ्य ज्ञान हो सकता है।

भारत की प्राचीनतम एवं महत्तम नदियों का वर्णन सर्वप्रथम ऋग्वेद के दशम मण्डल में प्राप्त होता हैं।

सरस्वती सरयुसिन्धुअम्रितमिर्महोमहीख्सायन्तु वक्षणी। देवी रायो मातरः सदयिरन्योघृतवत्यो मधुमन्नो अर्चत। 10/5/64.9) इत्यादि में सरस्वती-सिन्धु और सरयु मही आदिका वर्णन मिलता है ।

रामायण और महाभारत में तो नदी एवं तीर्थों का अन्योन्याश्रय सम्बन्ध प्रतीत होता है। प्रस्तुत लेख श्री मद्भागवत में नदी चित्रण शीर्षक से आलोच्य ग्रंथ भागवत ही स्वीकृत किया हैं। सर्वप्रथम नदी शब्द के अर्थ अनुसंधान आवश्यक है।

नदी शब्द सभी कोषग्रन्थों में प्राप्त होता है।

अमरकोष के अनुसार -

नदी के बारह नाम कहे गये है।

नदी शब्द - णद अव्येक्ते शब्दे से

पचादिषु हित होने से टिहडंच से टीप होता है। जिसका अर्थ है अव्यक्त शब्द करने वाली और चारनाम रामाश्रमी से प्रक्षिप्त श्लोक में कहे गये है। अर्थात सोलहनाम नदीवाची स्कीकृत हैं।

यास्क के निरुक्तानुसार 36 नदीवाचीं हैं।

\section{नद्याकरमात-नदनाइमाभवन्ति}

शब्दवत्य: - इत (2/7 पाद)

अर्थात् शब्दावाली होने के कारण इन्हे नदी कहा गया। इन नदियों का वर्णन वेदों में गौणरुप में अन्य देवतावाले मंत्रों के प्रयोग में हुआ हैं।

ऋग्वेद में एक प्रसंग है जिसमें विश्वामित्र ऋषि जो सुदास के पुरोहित थे वे विपासादतद्रु के संगम पर पहुंचे और स्तुति पूर्वक उन्होंने कहा हे नदिओं तुम कम जलवाली हो जाओ। निरुक्त में कमजलवाली और ऋतावरी (बहुत जलवाली नदियाँ) वर्णन मिलता हैं। वहाँ नदियों का बहुत ही सुन्दर उत्तर वर्णित है कि जैसे पुत्र के लिए दुग्धपान कराती हुई माँ झुक जाती हैं उस प्रकार मनुष्यों के लिए कम थाह वाली हो जाये लेकिन कम जलवाली नहीं। इस प्रसंग से यह सिद्ध है कि प्रकृति के द्वारा मनुष्य की कितनी सहायता स्वतः प्राप्त है फिर भी मनुष्य इस प्रकृति के वरदान को नहीं समझ पा रहा है।

भारतीय संस्कृति में नदियों का पर्वतों का और नदी सम्बन्धी तीर्थों का धार्मिक महत्व ही नही अपितु सांस्कृतिक, राजनैतिक तथा वैज्ञानिक भी महत्व हैं। केवलधर्मावलम्बी ही नहीं अपितु अन्य धर्मावलम्बी भी नदी के महत्व एवं उपादेयता स्वीकार करते हैं। भारतीय संस्कृति एवं सामाजिक विकास में नदियों का प्रमुख स्थान हैं।

श्रीमद्भागवत में नदी वर्णन -

पौराणिक वाड्ंगमय में वैसे तो प्रायः सभी पुराणें में भूगोल और खगोल के वर्णन के संदर्भ में नदियों का वर्णन प्राप्त हैं। तथापि यहाँ श्रीमद्भागवत के आलोक में नदी वर्णन ही ध्येय हैं। 


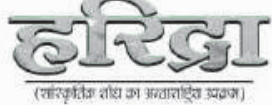

द्वादशसकन्धात्मक श्रीमद्भागवत के पंचम स्कन्ध में भूगोल एवं खगोल वर्णन में नदियों का उल्लेख महर्षि व्यास ने किया है।

श्री भागवत में प्रधान रुप से 8 स्थलों में नदी प्रसंग है $(5 / 17,5 / 20-88 / 24,10 / 15$ आदि में)

श्रीमद्भागवत में एशिया की सात नदियों का वर्णन प्रधानतया किया गया है। जिसके नाम इस प्रकार है-

(1) सीता - का क्रम सन्दिग्धं है

(2) अलखनन्दा - दक्षिण भारत में प्रवाहित

(3) चक्षु (वक्षु, स्वक्षु)

(4) सिन्धु - पांचजन्य में

(5) हादिनी

(6) नलिनी

(7) पावनी

इन नदियों के अतिरिक्त भारत वर्ष के वर्णन में $(5 / 20 / 4$ तथा $5 / 11 / 27)$ में नौ द्वीपों में विभिन्न नदियों का उल्लेख आता है। जो प्रायः 136 नदियों का नामोल्लेखविभिन्न प्रसंगों में मिलता है। कुछ अन्य नदियों का भी विभिन्न प्रसंगों में संदर्भ संकेत प्राप्त होता है। अतः कुल 214 नदियों का श्री मद्भागवत में चित्रण है।

यहाँ प्रसंगानुसार प्रमुख नदियों का यथासम्भव वर्तमान भौगोलिक स्थिति के आधार पर वर्णन प्रस्तुत है।

प्रमुख नदियों में सप्तनदियां ही विशेषरुप से वर्णनीय हैं। प्राय पुराणों में भी वेदवर्णित नदियों को श्रेष्ठ कहा जाता हैं।

इमं गंगे यमुने सरस्वति शतुद्रिस्तोमं सचता परुष्णाया। असिक्नया मरुदवृधे वितस्तयार्जकीये श्रृणुद्या सुषोमया।। ( ऋ. वे. $10 / 75 / 5)$

भारत के प्रान्तदिसीमा विभाजन में पर्वतों और नदियों की उपयोगिता सिद्ध हैं। ऋग्वेदवर्णित नदियों का स्थान भारतीय संस्कृति में धार्मिक राजनैतिक और व्यवसायिक दृष्टि से महत्वपूर्ण रहा हैं। इन्हीं कारणों से भारत भूमि आदिकाल से सस्यश्यामला सुषमा सम्पन्नता एवं समृद्धशालीनी रही हैं। वेद और पुराणों के अनुसार गंगादि कुछ प्रधान नदियॉ इस प्रकार हैं।

श्रीमद्भागवत में -

(1) चन्द्रवसा (2) ताम्रपर्णी (3) अवरोदा (4) कृतमाला (5) वैहायसी (6) कावेरी (7) वेणी (8) पयस्विनी (9) शर्करावर्ता (10) तुगःभद्रा (11) कृष्णा (12) वेण्या (13) भीमरथी (14) गोदावरी (15) निर्विन्धाया (16) पयोष्णी (17) तापी (18) रेवा (19) सुरसा (20) नर्मदा (21) चर्मण्वती (22) सिन्धु (23) अन्धः (24) शोण (25) महानदी (26) वेदस्मृति (27) ऋषिकुल्या (28) त्रिमासा (29) कौशिकी (30) मन्दाकिनी (31) यमुना (32) सरस्वती (33) दृषद्वती (34) गोमती (35) सरयू (36) राधस्वती (37) सप्तवती (38) सुषोम (39) शतद्रु (40) चन्द्रभागा (41) मरुदवृधा (42) वितस्ता (43) असिफि (44) विश्वा

\section{प्लक्षद्वीप}

(45) अरुणा (46) नृम्णा (47) आड़िंग्रसी (48) सावित्री (49) सुप्रभाता (50) ऋतम्भरा (51) सत्यम्भरा

\section{शलयमलीद्वीप}

(52) अनुमति (54) सिनीवाली (55) सरस्वती (56) कुहू (57) रजनी (58) नन्दा (59) राका

\section{कुशद्वीप}

(60) रसकुल्या (61) मधुकुल्या (62) मित्रविन्दा (63) श्रुतविन्दा (64) देवगर्भा (65) घृतच्युता (66) मन्त्रमाला

कोस्यद्वीप

(67) अभया (68) अमृमतौद्या (69) आर्यका (70) तीर्थवती (71) वृत्तिरूपवती (72) पवित्रवती (73) शुक्ला

\section{शाकद्वीप}

(74) अनघा (75) आयुर्दा (76) उमयस्मृष्टि (77) अपराजिता (78) पंचपदी (79) सहस्त्रसुति (80) निजधृति 
(1) गंगा

गम लृ गतौ धातु से गतगव्य द्यो सूत्र से गन प्रत्यय लगाकर टाप करने से गंगा शब्द की निष्पति होता है जो हमेश चलें उसका नाम गंगा हैं। गच्छति इति गंगा।

वेदों में गंगा -

ऋग्वेद के 10-75-5 में अन्यनदियों के साथ गंगा का वर्णन प्राप्त होता है। सम्पूर्ण ऋग्वेद में दो बार गंगा का उल्लेख हैं।

\section{ब्राहम्ण ग्रंथों में -}

शतपथ ब्राहम्ण

तैत्तरीय ब्राह्ण्ण $(2 / 10)$ में गंगा का चित्रण हैं।

रामायण और महाभारत में तो अनेकों बार इसकी चर्चा की हैं। वर्तमान गंगा का भौगोलिक चित्रण करने की आवश्यकता नहीं है संसार इससे अवगत हैं।

पर्याय -

अमरकोष के $(1 / 10 / 31)$ में आठनाम गंगा के पर्याय रुप से वर्णित है।

गंगा विष्णुपदी जहुतनया सुरनिम्नगा।

भागीरथी त्रिपथगा त्रिस्त्रोता भीष्मसूरपि।।

हेम ने चार नाम दिये है। कुल 12 नाम प्राप्त हैं।

\section{(2) सिन्धु -}

यह नदी ऋग्वेद के $(10 / 64 / 9)$ में वर्णित है। वहॉ सरस्वती और सरयु के साथ धृतवत मधुमय पयपान करने के लिए स्तुति रुप में वर्णित महाभारत के अरण्यपर्व में श्रीमद्भागवत के पचंमर्कन्ध में इसकी र्थिति कहीं गयी हैं। वाल्मिकी रामायण में भी इसका वर्णन प्राप्त होता है।

\section{वर्तमान स्थिति -}

इसका उदगम स्थल कैलाश के उत्तर हिरणश्रृग (मैनाक) बिन्दु सरोवर से हैं। भागवत के अनुसार गंगा की सप्तधाराओं में से एक है। जे. एच. दवे इसे मानसरोवर से निकला हुआ मानते हैं। वायुपुराण के 47 अध्याय में लिखा है कि इसका उदगम वैधूत पर्वत से है। यह नदी पंजाब से पश्चिमोत्तर सीमा बनाती हुई मुलतान से होकर मीठानकोट से आगे सिन्ध प्राप्त में होती हुई अनेक नदियाओं को लेकर समुद्र से मिलती है।

9 सहायक नदियाँ है।

(3) सरयु -

ऋग्वेद में $(4 / 30 / 18,5 / 23 / 9,10 / 64 / 9)$ वर्णित हैं। ऋग्वेद में हस्व उकार का प्रयोग हुआ है। परन्तु रामायण, महाभारत और श्रीमद्भागवत में दीर्घ उकारका प्रयोग हुआ हैं। श्रीमद्भागवत में $(9 / 10)$ में वर्णित है। इसके उत्पति की अनेक कथायें प्राप्त हैं।

भागवत के अनुसार देवों के प्रार्थना पर वाशिष्ठ ने कैलाश की ओर बहने वाली गंगा को दिव्य सरोवर से सरयु का उदगम हुआ। रामाश्रमी $(1 / 24 / 9)$ सर:प्रवृत्ता सरयू:

\section{स्थिति :}

इस नदी में घाघरा का संयोग होने से अयोध्या में सरयु कहलाती है। मानसरोवर से निकलकर इसका नाम कौडियाल नदी भी हैं। नेपाल को पार करती हुई जहाँ इसका नाम वसिष्ठी, गौरी, काली आदि मिलकर आगे घाघरा बनती है।

भारत की सप्तपुरियों में अयोध्या से होती हुई गोरखपुर फैजाबाद आजमगढ की सीमा बनाती हुई बरहज में उत्तर राप्तीनदी में मिलान होता हैं। आगे बलिया से जाकर छपरा के पास गंगा से मिल जाती हैं। इस संगम को भृगुतीर्थ या महाप्रयाग कहा गया है। इसका प्रवाह प्राय 600 मील लम्बा हैं।

यमुना - 


\section{ब्रांखित्रा

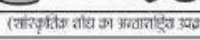

ऋग्वेद में इसका भी उल्लेख प्राप्त है। प्रजापति ने इसके किनारे 1000 यज्ञ किये। श्रीमद्भागवत के दशमस्कन्ध में इसका वर्णन प्राप्त हैं। ब्रह्मण्ड पुराण में इसका वर्णन अत्यंत रोचक मिलता है। यमुना का उद्गमस्थान गढवाल राज्य के जनुनोत्तरी ढाई कोस उत्तर बन्दरपुच्छ पर्वत से हैं।

इस चोटी का नाम कलिन्द है सम्भ्वतः इसीलिए इसको कालिन्दी कहा गया हैं। सहारनपुर जिले के क्षेत्र से होती हुई पंजाब की सीमा बनाती हुई मथुरा ब्रजमण्डल से होकर इटावा से आगे चम्बल नदी इसमें मिलती हैं। हमीरपुर होकर प्रयाग में गंगा से मिलती है। इसकी लम्बाई उद्गम स्थल से 430 कोस हैं। श्रीमद्भागवत में इसका महत्व इसके तटवास का पुण्य वर्णित हैं। वेतवा बाणगंगा घसानेव केन इनकी सहायक नदी हैं। (इसके 4 नाम (अमर) से प्राप्त होते है।)

\section{(5) दृषद्वती -}

ऋग्वेद के $(3 / 23 / 4)$ पंचविशब्राह्म्ण $(25 / 10 / 13)$ में इसका वर्णन प्राप्त होता है। महाभारत के शान्तिपर्व में सरस्वती के साथ इसका निर्देश है। वामन पुराण और मनु रमृति में कहा है कि सरस्वती और इसके बीच के क्षेत्र को ब्राह्मवर्त कहा है। श्रीमद्भागवत के $(5 / 11 / 16)$ में इसे श्रेष्ठ नदियों में गिनागया हैं।

जनरल कनिंधम के अनुसार दक्षिण पश्चिम में बहने वाली राक्षी नदी है। महाभारत के अनुसार कुरुक्षेत्र इसका दक्षिणीसीमा प्रान्त बताया हैं। वामनपुराण में फलकी वन में इसकी स्थिति बतायी है।

(6) सरस्वती -

वे विश्वसरस्वती श्रितायूसि देव्याम $(2 / 41 / 17) 10 / 64 / 9$ के अनुसार यह देवनदियों में मान्य है मनु कै अनुसार- सरस्वती दृषदवत्योर्नद्योदर्थ नन्तर। तं देवनिर्मितं देशं बह्मावर्तप्रचक्षते है।

\section{मनु. 2/17-18}

ऐतरेया ब्रा. (2/19) ताण्डवा, (अ. 25 खण्ड10सू. 1)

महाभा. $3 / 29 / 12$ के अनुसार यहाँ देवर्षि राजर्षि और महर्षियों ने सारस्वत यज्ञ किये हैं। शल्यपर्व के अनुसार नैमिषारण्य में द्वादशवर्षतक यज्ञ किये गये।

श्रीमद्भागवत के $5 / 12$ में इसका उल्लेख मिलता है वैसे तो श्रीमद्भागवत में इसका वर्णन 9 स्थलों में प्राप्त है।

ऋ. 7/7/2-8 में इस नदी में पर्याप्त जल था जिसका ब्राह्मणकाल में लोप हो गया इसके तट पर 32 तीर्थों का उल्लेख महा. श्रीमदभा. में प्राप्त होता है। इसका उद्गम स्थल उत्तर है - 9 इसका संगम प्रया में गंगा-यमुना में होता है (भा.विष्णु) - उदगम माण्डरकर सं. आलो- 1 कुरुक्षेत्र में है।

2. जनरलकनिंघम पिहोवा में है।

(3) महाभारत के अनुसार प्लेक्षप्रसबण पर्वत से है वामन पुराण 32/3-4) के अनुसार ब्रह्मसर बद्रिकाश्रम 8 कि.मी. दूर है।

गोमती - यह वैदिक कालीन नदी है। (ऋ 8.24.30) में इसकी स्तुति की ही श्रीमद्भागवत में $5 / 20-4$ में इसका उल्लेख है।

\section{भौगोलिक स्थिति -}

$1-$ महाभारत (3-48-4) के अनुसार ने नैमिषारण्य में स्थिति है।

$2-$ आर्के के अनुसार ऋग्वेद वार्णितगोमती से यह भिन्न है।

3- चार स्थानों में इसकी स्तिथि दर्शायी गई है।

1. ऋग्वेद के कुमा और क्रमु नदियों भी स्थिति के मध्य सिन्धु की सहायक गोमल ही है $(8.24 .30 / 10$. 75.6)

2. द्वारका के समीप -

3. हिमालय से निकलकर वाराणसी के समीप

(8) सोण - सोन श्रीमद्भागवत $5 /$ वायुपुराण के अनुसार यह नद है। विन्ध्य पर्वत का एक शिखर है अमरकंटक। जिसका नाथ सुरथ अद्रिजा कहा है पारिपात्र पर्वत है। इम्पार्टल इण्डिया (भार. वि. भवन) जे. देव) 


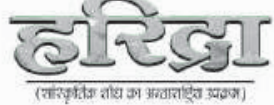

इसको सोननदी भी कहते है।

(9) ताम्रपर्णी - यह पाण्डय प्रदेश की शुभ नदी है जो मतल पर्वत से निकलती है तमिलनाडु की सर्वाधिक महत्वपूर्ण नदी है। ग्रीष्म में भी पर्याप्त पानी रहता है। भागवत में।

ताम्रपर्णी नदीयत्र कृतमाला यमस्विनी

कावेरीच महापुण्या प्रतीची च महा नदी (भाग $54 / 3$

कृतमाता ताम्रपर्णी पुष्यजासूत्पलावती (मार्क.अ

यह नदी 35 कोस लम्बी है इतने में ही इसमें 8 बाँध बंधे है।

(10) भीमा (भीमरथी) पूना जिले के भीमशंकर ग्राम में सह्याद्रिपर्वत माला से यह निकलती है। भीमशंकर द्वादशज्योर्ति मंदिर है।

इसमें धोड मूता नीरा जो वहीं पर्वत से निकलती है इसकी सहायकत है पूना मूता नदी पर ही बसा है। आगे गुलमर्ग जिले में कृष्णा से मिल जाती है। भाँभर भी मैभवती- चालुक्य पुलके के शिलालेख में यह उल्लेख है।

(11) करतोया- कर तोया सदानीरा (अमर) में सदानीरा, का पर्याय करतोया कहा है भाग-5 में मार्क वामनपुर और महाभा. यह हिमालय से निकलती
है प. बंगाल रंगपुर, दीनाजपुर तथा वोगराजिले से बहती है इसे गण्डकी और सरयु के मध्यमाना है जलपाइगुडी के उत्तर पश्चिम से दक्षिण की और दल हातिमा नदी में मिलती है इतिहास के अनुसार इसके किनारे। 1205 में मुहम्मद वस्तियार खिजली और 1498 में उल्लउद्दीन हुसने ने तिब्बत असफल चढाई की थी उसमें इस भाग का उल्लेख है वर्तमान में यह पावना जिले से 15 कोस पूर्व आत्रेयी नदी में मिलकर गंगा में मिलती हैं यह सौ कोस लम्बी है।

इस प्रकार भारतीय नदियों का चित्रण संस्कृत साहित्य में प्राप्त है। प्रायः नदियों का भौगोलिक वर्णन है परन्तु यहॉ प्रस्तुत नही हो सकता। नदियों का सम्बन्ध तीर्थ, धर्म और भूगोल से है। अतः भरतीय नदियों हमारी अनुपमेय प्राकृतिक सम्पदा है। इस सम्पदा का रक्षण करना प्रत्येक भारतीय का कर्तव्य है। क्योंकि इनकी रक्षा होगी तभी हमारी एवं पर्यावरण की रक्षासम्भव है।

- संयुक्त प्रवक्ता

व. सं. म. वि महाराज सयाजी विश्वविद्यालय वडोदरा (गुजरात) 